\title{
Comunidades posconflicto en el departamento de Junín: el valle del Canipaco y Pariahuanca
}

\section{RESUMEN}

Estudio exploratorio que compara dos zonas rurales post-conflicto de la sierra central del Perú y como las características de estas no solo implicaron distintas formas de la guerra interna, sino también distintas formas de liderazgo y de reconstrucción de la comunidad. Lo que se quiere mostrar finalmente es la dinámica actual de estas regiones en un contexto de modernización, crecimiento económico e interconexión creciente.

Palabras Clave: postconflicto; liderazgo; desarrollo comunal; sierra central.

\section{Post-conflict communities in the Department of Junin: the Canipaco valley and Pariahuanca}

\section{ABSTRACT}

Exploraty study that compares two rural post-conflict in the central highlands of the Perú and as the characteristics of these involved not only different forms of the civil war, but also different forms of leadership and community reconstruction. What is wanted to show finally is the dynamic current of these regions in a context of modernization, growth economic and interconnection increased.

KeYwOrDs: post-conflict; leadership; community development; central highlands.

\footnotetext{
* Departamento de Antropología, Facultad de Ciencias Sociales.
} 
E ste artículo compara dos zonas rurales posconflicto y cómo su diferenciación microrregional en el departamento de Junín pudo haberse relacionado con formas propias del conflicto interno y, luego, en distintos tipos de liderazgo comunal. En periodos de crisis social creemos que las comunidades campesinas en general, recurrieron a sus propias formas de cohesión, relacionadas a su vez, con la dinámica de la región central.

Este incipiente trabajo permitirá registrar los cambios en las comunidades comprometidas en el lapso de la posguerra y nos obliga, además, a reconstruir mínimamente el panorama del conflicto interno tardío (1986-1996) en las áreas de estudio.

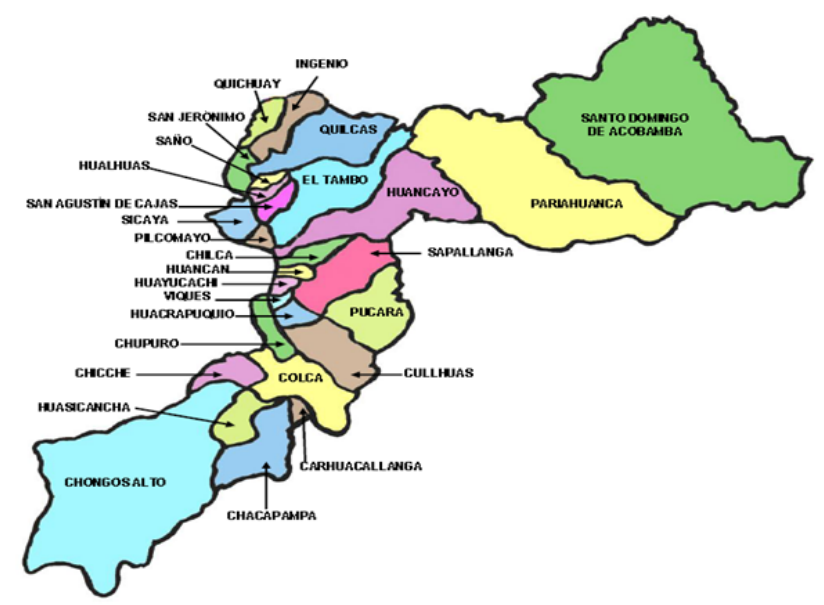

Figura 1. Mapa de la provincia de Huancayo.

El liderazgo rural ha sido evaluado desde distintas perspectivas. Algunas propuestas se han centrado en la capacidad de dirigir movimientos campesinos (líderes "transformacionales»), otras en la negociación de conflictos («transaccionales»). En ambos casos, parece cierto que estos líderes o dirigentes suelen tener experiencias extra-rurales significativas, pareciese que las vivencias en escenarios urbanos y estratificados permiten que surja una "conciencia subalterna» que luego la transmiten a sus comunidades de origen.

Del mismo modo el capital cultural, es decir, el tránsito por la educación "oficial», permite ganar legitimidad ante sus paisanos y esta condiciona generalmente la habilidad en el manejo de las relaciones con el poder en general: autoridades distritales, subnacionales, empresas y políticos del dominio nacional. Sobre esto último, ha sido la propia legislación estatal sobre las comunidades campesinas, la que ha normalizado la actuación de los dirigentes y los estándares que deben seguir. La habilidad de estas relaciones con el poder, más allá de la aldea rural, es en buena cuenta la que galvaniza sus cualidades. Las ideas e imaginarios que convocan pueden ir desde el radicalismo político hasta la reutilización de repertorios culturales "tradicionales», pero bajo nuevos contextos y marcos significativos. Aunque, en buena cuenta, ambos portafolios son utilizados indistintamente y en determinados momentos.

\section{La zona altina}

El valle del Canipaco, ubicado en la parte occidental del valle del Mantaro, tiene características propias y hasta cierto punto antitéticas con la parte oriental. La zona occidental que en el lenguaje regional se le denomina como la "zona altina», tiene mayor extensión, no sobrepasa en sus cotas más altas los 4,000 metros sobre el nivel del mar y es climáticamente seca. Posee terrazas escalonadas dedicadas fundamentalmente al cultivo de los cereales (Mayer 1981), aunque su potencial más importante haya sido desde tiempos muy antiguos el pastoreo y la crianza de animales.

En efecto, la pampa Laive-Ingahuasi, una altiplanicie que corona el valle del Canipaco, fue desde el periodo colonial un importante asiento de actividades ganaderas. Los cacicazgos huancas accedieron a sus pastos constituyendo haciendas, mientras que en la parte baja del valle, los pertinaces ayllus controlaban las ricas tierras agrícolas. En el siglo XIX estas tierras pasan a un puñado de familias con liderazgo regional (Valle, Valladares, Olavegoya) que modernizan en algo sus haciendas.

Pero es entre 1905 y 1910 que grupos de poder económico asentados en la capital reordenan el territorio altoandino y expanden las haciendas, muchas veces a costa de las tierras comunales. Es también el inicio de su capitalización, pues implementan importantes cambios en la producción, como fue la introducción de ovinos de raza.

Según Martínez Alier (1973), durante los siglos XIX y XX ya no se crean más haciendas, lo que hay es la transformación de propiedades de «papel» a los

1 Desde Vista Alegre discurre un camino de herradura que lleva directamente a la zona de Riegopampa en el distrito de Vilca que pertenece al departamento de Huancavelica, en su trayecto se ubica la cueva de Waraqomachay — apenas estudiada - que ofrece al visitante impresionantes escenas de cacería de camélidos sudamericanos. Ver el solitario trabajo de Chahud y Ríos (1978). 
intentos de tomar posesión efectiva de sus tierras y sobre todo, de desalojar a los campesinos ya instalados en sus linderos. Los movimientos campesinos en el centro del país, serían entonces la lucha por el intento de expulsión de los campesinos y de estos de no ceder ante los propietarios.

Entrado el siglo $\mathrm{xx}$, estos grandes propietarios iniciaron una agresiva campaña de modernización creando la Sociedad Ganadera del Centro y es ahí, donde ocurren hechos que podríamos definir de paradojales. En primer lugar, su tecnificación se debió al uso de mano de obra las comunidades que gravitaban sobre las haciendas. Esta fuerza de trabajo barata y atada a formas domésticas de producción, permitió el rápido progreso de la ganadería extensiva. Sin embargo esta ventaja comparativa sería trocada más adelante en su antítesis, es decir en la posterior crisis desatada en el último tercio del siglo xx.

Los niveles crecientes de inversión y rentabilidad de las haciendas constituidas (Laive, Antapongo, y Tucle), acicatearon la conciencia comunal por obtener mejores condiciones de trabajo y de reclamar por las tierras despojadas, como sucedió con las comunidades de Huasicancha o Chongos Alto. Pero también permitió un hecho, que no solo significó la ventaja comunera que a la larga socavaría la gran propiedad, sino que ofrecía la oportunidad de discutir los alcances del desarrollo capitalista en los Andes.

Comparado con otros cielos, la incapacidad de proletarizar a los campesinos de la zona, significaba en cierto modo la debilidad estructural del capitalismo periférico para destruir las formas domésticas de propiedad/producción (Alier 1973, Remy 1976). También validaba la histórica escasez de mano de obra en las haciendas y las sinuosas negociaciones entre terratenientes y comuneros a lo largo y ancho de la sierra. Es por eso que al ganado "huaccha» (las ovejas «chuscas») de propiedad de los pastores al servicio de la hacienda, les fueron permitidas apacentar con el ganado de raza.

\subsection{El modelo SAIS}

La reforma agraria militar transformó las haciendas altoandinas en Sociedades Agrícolas de Interés Social, forma que encajaba en los modelos de cooperativismo rural que traducían el ideal de un «modelo autogestionario, ni capitalista ni comunista». Estas asociaciones se diseñaron respetando escrupulosamente los límites terratenientes y heredaron de paso, los conflictos con las comunidades de su hinterland. Esta histórica conflictividad sería junto a los límites de la proletarización, los dos factores que a la larga, sellarán su bancarrota. En ese sentido, no solo estaban intactas las relaciones de dependencia sino también, los estilos de vida y los imaginario respecto de la hacienda cono núcleo de prestigio y que el nuevo modelo no había podido o querido revertir.

El autor de este artículo participó como practicante en la División de Desarrollo Comunal de la SAIS y fue testigo de cómo en las Unidades de Producción, se replicaba el estilo excluyente de las antiguas haciendas. El administrador ahora un ingeniero, tenía a su servicio un mayordomo, poseía su propio cocinero, distante del «refectorio" donde se alimentaba el resto del personal empleado. Este hecho y otros, fomentaban la discusión entre la izquierda —incluido SL_ de si estas empresas eran capitalistas o semi-feudales (Montoya 1987)

Téofanes Chambergo un testigo de la época relata: «Y casualmente esa vez más nos dedicábamos cuando estaba el hacendado de la SAIS porque no teníamos muchas tierras, por eso también bastante gente a emigrado a las ciudades, entonces es la razón de que nosotros hemos intentado recuperar nuestras tierras...» (Reina 20013: 167).

Como veremos más adelante, Sendero Luminoso utilizará estas «debilidades» para obligar a las comunidades campesinas arremeter contra el modelo de la reforma agraria. Antecedentes los había: gracias a las formas de trabajo comunal de las comunidades ahora convertidas en socias, se incorporaron 1,400 hectáreas de pastos, así como la desviación de las aguas del río Quillacocha entre 1972 y 1975 (Medianero 1983).

Sin embargo, la renta en trabajo transferida a la empresa se traducía en una débil salarización (al igual que en las minas) como consecuencia del subsidio de la economía campesina. Este sistema de explotación tuvo también una historia de protestas por parte de las comunidades campesinas. En 1925 las comunidades de Potaca, Chicche y Quishuar estarán enfrentadas con la hacienda Laive-Ingahuasi. En 1946 los pastores de estas haciendas altoandinas exigían de forma generalizada, demandas salariales. En 1947 los comuneros de Chongos Alto intentan recuperar tierras de la hacienda de Antapongo, en un movimiento cruento conocido como del «cañón blanco». ${ }^{2}$

2 El 21 de enero de 1947, cinco comunidades entre las que se encontraba Chongos Alto, invaden las tierras de la hacienda. Un batallón militar llegado de Huancayo los enfrenta, dejando cinco comuneros muertos. 
En 1963 la comunidad de Huasicancha invade y se apropia de tres mil hectáreas de Tucle; en un hecho sin precedentes que no solo se convertiría en emblemático para la historia de los movimientos campesinos del país (Smith 1989), sino que también se instalará en la memoria colectiva de la región.

\subsection{La guerra del Canipaco}

Para 1986, el departamento de Junín era una de las regiones más afectadas por la guerra interna, a tal punto que en 1989 las Fuerzas Armadas convertirán a Pasco, Junín y Huánuco, en el «centro de gravedad» de las operaciones antisubversivas (AH 2013).

Sendero llega a la zona a mediados de los años ochenta. Dentro de su estrategia regional, el valle del Canipaco tenía una importancia medular, pues esta organización no solo se apeaba a una historia de conflictos comunidad/hacienda, sino que también era un corredor que les permitía abastecerse de ganado y acémilas, como ruta de tránsito hacia la cuenca del río Cañete y el norte de Huancavelica.

En efecto, la zona conectada a la costa había sido históricamente una despensa por el cual los campesinos del Canipaco, se desplazaban estacionalmente para trabajar en los fundos algodoneros y les proveía de bienes importantes como frutos secos y aguardiente, bienes transables y apreciados por el bolsón rural.

Entre 1989y 1989, el Partido Comunista (SL), realiza cinco incursiones en la comunidad de Llamapsillon. Las columnas armadas conducidas por los camaradas «Ramón» y «Nelly» asesinan en 1987 a Luis Capcha el administrador de Laive. En mayo de 1988 atacan los puestos policiales de Chongos Alto y Yanacancha, este último ubicado en la cuenca del río Cunas.

En agosto expulsan a los miembros del proyecto PROCAD, en manos de sacerdotes jesuitas, y en noviembre incendian las instalaciones de las exhaciendas de Runatullo, Punto y Acopalca, propiedades de la SAIS Cahuide, y ubicadas en la parte este del valle del Mantaro (CVR 2004).

Un año antes también habían ocurrido intentos de Huasicancha por recuperar tierras. Es una época de gran activismo comunal vinculado a la Federación Campesina del Perú (FENCAP) que dependía del partido aprista. Entre sus dirigentes estaban Antonio Tácunan, Martín Ramos, Elias Yurivilca y Narciso Orihuela. Todos vinculados en cierto modo al célebre Elías Tácunan quien trabajaba en la Cerro de Pasco Corporation, pero mantenía vínculos con las comunidades del Canipaco. Fue fundador además, de la Universidad Comunal del Centro, el punto más alto de la autonomía campesina en la región.
En diciembre de 1988 —cuando Alan García, entonces presidente, decreta el "estado de emergencia» en el departamento de Junín- destruyen el grifo Cahuide en Huancayo, también propiedad de la empresa asociativa. Por lo visto entre las actividades de Sendero estaban el de petardear al modelo y aparentemente erigir la alternativa comunal siempre y cuando, está estuviese aliada o fuese supérstite de los maoístas. Su estrategia de inserción en la zona, era pues aprovechar el descontento y la animadversión histórica existente.

En un primer momento pudieron haber existido simpatías, sobre todo cuando subió la temperatura de los conflictos no solo de las comunidades socias sino incluso el de los campesinos frente a los propios trabajadores de la SAIS. Teniendo en mira el hecho de que la zona estaba conectada con la zona de Yauyos en su ruta hacia el valle de Cańete, tuvieron el apoyo entre otras comunidades, de Langaico, perteneciente al distrito de Laraos.

Ubicada a 4,300 metros de altura, sus habitantes eran básicamente pequeños ganaderos y no solo anhelaban las tierras de la SAIS sino también incluso el de las comunidades. Lo cierto es que por mucho tiempo los residentes del Canipaco identificaron muchas veces a los militantes de Sendero como «langaínos».

En diciembre de 1983 dinamitan Laive. Entre 1987 y 1988, se instalan «Comités Populares» en Chongo Alto, en esos mismos años se ataca nuevamente a Laive. En 1988 se instalan nuevas autoridades nominadas por sendero en Chongos Alto y Chacapampa.

La inestabilidad en la SAIS Cahuide era tal, que en 1988, la Asamblea General de Socios, rentaba sus predios a precios irrisorios, por ejemplo en una oportunidad vendió 40 hectáreas de terreno a 500 dólares americanos. Estaba sucediendo lo que el Partido Comunista SL, proclamaba: "arrasar con la semi-feudalidad en el campo». En 1989 saquean las Unidades de Producción de Tucle y Antapongo, en la que también participarían comuneros de Palmayoc, Palaco, Llamapsillón y Chongos Alto, en donde no solo se apropiaron de tierras, sino también de bienes y enseres.

El cenit de la violencia estalla en 1989. El 12 de enero asesinan en el paraje de Palmayoc a un dirigente comunal de Chicche y al antropólogo Manuel Soto quien dirigía la Ong CICEP (Centro de Investigación Campesina y Educación Popular) afiliada al PCR (Partido Comunista Revolucionario) y que operaba en la zona. El 12 de abril del mismo año, cerca de 
40 senderistas reúnen en la madrugada en la Plaza de Chongos Alto, a cerca de 16 personas que viajaban en un autobús a la ciudad de Huancayo. De ellos son asesinados 12, la mayoría dirigentes comunales.

El desconcierto y la zozobra ante esta arremetida dominaron a las comunidades en un primer momento. $\mathrm{Su}$ respuesta ante estas pérdidas y el estar ahora enfrentados en una guerra, los obligó a optar por dos vías: la primera de manera diseminada y que involucró a decenas de familias de la zona, que emigraron a Huancayo, Cañete y Lima. ${ }^{3}$

La segunda fue la de apoyar e incorporarse en las rondas de autodefensa organizadas por el Ejército que llega a la zona en 1991 cuando instala una base militar en Vista Alegre y conectada con el importante destacamento de Manta al norte de Huancavelica.

Merced al D.L. 740 de 1991 que oficializaba la formación de rondas de autodefensa, es que en 1992 se instala la primera Ronda en Chongos Alto, por los esfuerzos del comunero Zenón Lapa, pero antes ya el 24 de junio 1989, los comuneros de Llamapsillón habían solicitado reconocimiento de sus rondas. En 1990 se instala la base militar en Yanahuanca en el alto Cunas, si bien fuera de la zona, era vecina de algunas comunidades socias de la SAIS.

En 1992 el Ejército tenía registrado 1,568 ronderos en el Canipaco (AH 2013: 48). Para 1993, los senderistas habían sido «expulsados», iniciándose el lento retorno para iniciar la reconstrucción ${ }^{4}$.

\subsection{La reconstrucción}

Entre los escombros de Laive y Tucle (véase la fotografía del anexo), y las ruinas de la municipalidad de Chongos Alto, las comunidades del Canipaco empezaron su lenta reconstrucción aventajada por la migración pendular y su cercanía con la ciudad de Huancayo. De las rondas campesinas desactivadas y de la tradición letrada de los comuneros de Chongos Alto y Chicche,

3 Por la acción pionera del ingeniero Rigoberto Calle Escobar funcionario de la Sociedad Ganadera del Centro, es que marchan en los ańos 70, los primeros jornaleros hacia los ranchos ovejeros de Nevada y el norte de California (EE.UU.), iniciándose un drenaje importante de migrantes de la zona. También tenemos la significativa presencia de huasicanchinos en Milán. En ese sentido la presencia de los residentes de Chongos Alto en Lima y Huancayo es importante. En esta última ciudad poseen dos instituciones: la Asociación Cultural Chongos Alto y la Asociación Hijos Residentes de Chongos Alto

4 Sin embargo en el valle del Mantaro se habría otro frente. En 1992 se instala una guarnición militar en la Universidad Nacional del Centro, que sería el centro de estudios superiores más severamente castigado por la guerra interna. pero también de Colca y Carhuacallanga; los nuevos dirigentes comunales y alcaldes iniciaron la tarea de reavivar sus instituciones sociales y de continuar con sus actividades productivas.

Las 90 mil hectáreas que fueran propiedad de Laive, Antapongo y Tucle-Río de la Virgen, pasaron a manos de las comunidades, así como el proyecto ganadero-lechero de Ullapata. Este proceso de redistribución, pudo haber sido el principal motor de la lenta migración de retorno y que complementaba las remesas que venían del exterior.

Como mencionamos al inicio, la violencia impactó desigualmente en diferentes escenarios y en diferentes estratos de la población. En el caso que nos ocupa, muchos de los que organizaron la resistencia contra sendero pero también de los que participaron en ella, se ungieron después como dirigentes locales. La conexión con los residentes emigrados, con las autoridades regionales y su legitimidad obtenida, los hace protagonistas de por lo menos tres procesos interrelacionados:

a) Con su elección como alcaldes y dirigentes comunales van reconstruyendo el «tejido social» en las comunidades.

b) Ante la ausencia de la ayuda privada, el Estado se convierte en el principal protagonista del desarrollo en la zona, necesitando para ello, de intermediarios e interlocutores.

c) La expansión y el crecimiento del mercado regional, acerca aún más a esta zona con la importante ciudad de Huancayo, una de las más grandes de la sierra peruana.

\subsubsection{Una sociedad local en consolidación}

Hoy día la impresión que tiene el visitante de la zona es el de una sociedad fuertemente localista que los une una historia común en que la violencia y la importancia de la ganadería, son sus pivotes fundamentales. Pero también hay otro, menos estático y que alimenta la vida cotidiana de los comuneros; es su constitución migrante, que orillan entre el espacio rural del Canipaco y la ciudad de Huancayo, con proyectos cimentados en la imagen de modernidad que esta ciudad refleja: la casa construida y los hijos que se educan. Solo dos horas y media los separan de estos proyectos de vida y que se jerarquizan en distintos momentos y en desiguales ritmos. ${ }^{5}$

$5 \quad$ Según el Censo Nacional Agropecuario de 1994, el 38\% de las Unidades Agropecuarias de Junín tenían menos de 01 hectárea y el 26\% más de 


\subsubsection{La mancomunidad}

El valle del Canipaco, cuyos alcaldes también la denominan de «mancomunidad», está constituido por los siguientes distritos:

\section{CUADRO 1}

MANCOMUNIDAD DEL CANIPACO

\begin{tabular}{|l|c|c|}
\hline \multicolumn{1}{|c|}{ Distrito } & Año de creación & Extensión $\left(\mathrm{Km}^{2}\right)$ \\
\hline CHACAPAMPA & 1959 & 120,72 \\
\hline CARHUACALLANGA & 1941 & 13,78 \\
\hline CHICCHE & 1961 & 43,43 \\
\hline CHONGOS ALTO & 1907 & 701,75 \\
\hline HUASICANCHA & 1930 & 47,81 \\
\hline
\end{tabular}

Fuente: INEI

La denominación de «mancomunidad» fue constituida como una forma eficiente y conjunta de enfrentar los problemas del desarrollo local en una perspectiva microrregional. Fue creada por Resolución de Secretaría Nro. 033-2013-PCM/SD y está integrada por seis distritos, aunque uno, Chupuro, está ubicado en el extremo sur del valle del Mantaro, fuera del alcance de nuestra zona de estudio.

Chongos Alto es en cierto modo la comunidad emblemática que nos servirá como referencia de su reconstrucción social post-facto, luego de haber sido afectada por la violencia política. Chongos Alto es también una comunidad campesina. Tiene una organización dual: el barrio de Arriba y el barrio de Abajo. El primero tiene tres cuarteles: Mariscal Castilla, Unión y Santa Cruz. El segundo: 2 de Mayo, San Isidro y San José. ${ }^{6}$

Las fiestas de estos cuarteles, son a fin de cuentas el ciclo ritual del distrito. La fiesta de las cruces, del cañay quinto o la faena comunal del Lizinakuy que se realiza en agosto; ritualizan los vínculos sociales pues

05 hectáreas. Es decir el porcentaje del minifundio es mayor que el observado a nivel nacional (25\%) (Armendáriz et.al, 2011). Este hecho explica por lo menos tres aspectos: a) el minifundio está asociado a la baja productividad pues impide economías de escala y rentabilidad, b) este hecho determina la adopción de tecnologías, créditos y el carácter de las relaciones de trabajo y c) condiciona la alta movilidad intra y extra-regional, convirtiendo los ingresos salariales no agropecuarios en importantes dentro del portafolio familiar. Es por ello que para el 2007 , el $67 \%$ de la población departamental era urbana. El $66 \%$ de las industrias se concentran en Huancayo, de los cuales 67 de ellas, son pequeñas empresas

6 Por razones históricas en la sierra central, el imaginario republicano vinculado al igualitarismo y la fe en el progreso, caló en sus comunidades, por esa razón los barrios, ayllus o mitades fueron llamados "cuarteles» y las faenes comunales (aynis o minkas) pasaron a denominarse «república». despliegan un set de introductores que hacen posible la idea de comunidad: agentes, comisionados, delegados y mayordomos.

Actualmente tiene un proyecto de Cunamás, del Vaso de leche con 170 beneficiarios, Qaliwarma, Juntos y Pensión 65. Caritas, una organización de desarrollo social de la Iglesia Católica, posee un programa alimentario en la zona.

Existen además, un colegio secundario, dos escuelas primarias y una inicial. Si se observa el cuadro Nro. 3, la población escolar no es numerosa pero si constante. Muchos jóvenes de Chongos Alto prefieren estudiar en Huancayo dada su cercanía con la capital departamental.

Finalmente, una compañía llamada Fresnillo tiene actualmente un denuncio en el territorio de la comunidad para la explotación minera en la zona de Corihuasi.

\section{CUADRO 2}

COMUNIDADES CAMPESINAS DEL CANIPACO

\begin{tabular}{|c|c|}
\hline $\begin{array}{l}\text { COMUNIDADES } \\
\text { CAMPESINAS }\end{array}$ & ANEXOS \\
\hline \multirow[b]{2}{*}{ CHACAPAMPA } & $\begin{array}{l}\text { Antacocha } \\
\text { Cucho } \\
\text { Chacapampa } \\
\text { Huacán } \\
\text { Los Angeles }\end{array}$ \\
\hline & Oylumpo \\
\hline \multirow[b]{2}{*}{ CHICCHE } & $\begin{array}{l}\text { Chicche } \\
\text { Potaca } \\
\text { Quishuar } \\
\text { Santa Magdalena } \\
\text { Santa Rosa de Huacramasana } \\
\text { Yana Yana }\end{array}$ \\
\hline & Vista Alegre \\
\hline \multirow[b]{2}{*}{ CHONGOS ALTO } & $\begin{array}{l}\text { Chongos Alto } \\
\text { Llamapsillon } \\
\text { Palaco }\end{array}$ \\
\hline & Palmayoc \\
\hline COLCA & Laria \\
\hline
\end{tabular}

Fuente: Elaboración propia.

En mayo de 2016, se asistió a una asamblea comunal en Chongos Alto. Ahí, los pobladores se reunieron con representantes de la empresa minera. En general, no están en contra de la explotación minera, pero exigen que cuando se inicien las operaciones, sean beneficiados con regalías y empleo temporal. Ignoramos si la población es consciente 
de los posibles efectos a mediano y largo plazo de la actividad minera. Además tienen un litigio territorial con Huasicancha, lo cual hace fluidas las relaciones entre las autoridades distritales y las comunales para enfrentar este problema.
En el caso del Canipaco, supérstite del valle del Mantaro, los nuevos movimientos regionales no tuvieron ese cariz «étnico». Si bien es cierto, surgieron agrupaciones que eventualmente reivindicaban las raíces «wankas» o "xauxas», o utilizaban una

CUADRO 3

CENTRO EDUCATIVO PACHACUTEC, CHONGOS ALTO

\begin{tabular}{|c|c|c|c|c|c|}
\hline Año académico & 1 año & 2 año & 3 año & 4 año & 32 \\
\hline 2009 & 44 & 40 & 43 & 36 & 37 \\
\hline 2010 & 42 & 38 & 36 & 31 & 34 \\
\hline 2011 & 41 & 39 & 26 & 25 & 29 \\
\hline 2012 & 25 & 38 & 28 & 39 & 26 \\
\hline 2013 & 39 & 30 & 39 & 21 & 22 \\
\hline 2014 & 20 & 37 & 36 & 22 & 24 \\
\hline
\end{tabular}

Fuente: Unidad de Estadística, C.E. Pachacutec

Los datos someramente presentados, muestran que Chongos Alto reconstruyó con gran rapidez su organización social. El periodo de tranquilidad que va de 1995 a la actualidad, ha permitido que la sucesión política sea ininterrumpida y haya sido el escenario de participación de líderes locales, tal como nos muestra el siguiente cuadro. simbología ligada a la actividad rural, en realidad expresaban intereses vinculados al campesinado, pues los protagonistas de estos movimientos y agrupaciones son líderes comunales y profesionales de los «sectores medios» del interior del departamento.

Postura que al final de cuentas se corresponde con el desarrollo mercantil y la conexión intrarregional

CUADRO 4

CHONGOS ALTO: EVOLUCIÓN POLÍTICA

\begin{tabular}{|l|c|c|}
\hline \multicolumn{1}{|c|}{ Alcalde } & Año & Agrupación o movimiento político \\
\hline Severo Chambergo Milán & 1995 & Integración Comunera \\
\hline Graciano Romo Hilario & 1998 & (Revocado) \\
\hline Luz Goyzueta Soto & $1999-2001$ & Somos Perú \\
\hline Honorato Soto Siuce & $2003-2006$ & Unidad Nacional \\
\hline Evaristo Siuce Vilcapoma & $2007-2010$ & Juntos por Junín \\
\hline Marcelino de la Cruz Chambergo & $2011-2014$ & Acción Popular \\
\hline Cristhian Lozano Chambergo & 2014 & Perú Libre \\
\hline
\end{tabular}

Fuente: Municipalidad de Chongos Alto.

Los alcaldes elegidos representan en cierto modo, los nuevos escenarios de participación regional. Si en Huancavelica se trató de demostrar (tratando de replicar un artículo de Anahí Durand de 2006) que en el 2000 se erigen movimientos que no eran sustancialmente "étnicos», sino solo conjuntos mistis que utilizaban el utillaje cultural indígena para ocupar el espacio de poder que habían dejado los llamados partidos políticos «tradicionales» (Plasencia 2014). en el departamento de Junín. Es en ese campo que los alcaldes elegidos de Chongos Alto combinaron ese perfil regional con los de su localidad, en que la superación de la violencia política y la eliminación del corporativismo estatal son los pilares en el que hoy, atisban el futuro. 


\section{Pariahuanca: caminos cruzados}

Pariahuanca es una de las poblaciones más antiguas de la región. El viejo Cochangará que fundaron los dominicos fue junto con Santiago de Comas y San Antonio de Andamarca, los pueblos de los "Andes», pequeños valles calientes y orientales, casi una frontera amurallada con las regiones de Chanchamayo y Satipo. En el siglo XviII era ya un curato importante de la provincia de Jauja, que era como se denominada a casi toda la cuenca del Mantaro.

Fue creado como distrito en 1857 y en el pasado había sido asiento - al igual que en el Canipacode haciendas de propiedad del poderoso linaje de los Apoalaya. Solo que estas propiedades estaban más diversificadas, por las características climáticas de la zona. Los pastos de Ronda, Antarpa o Yauliyaco se complementaban con fundos productores de aguardiente como Huaribamba, Antarpa y Viejo Cochangará (Peñaloza 1995).

La parte oriental del valle del Mantaro donde está situada Pariahuanca, es más alta, con parapetos montańosos que rasguñan más allá de los 5 mil metros. Sin embargo por su cercanía a la selva central es que alberga una gran variedad ecológica y productiva.

En la historia económica de la región desde el siglo XIX, fue productora de aguardiente de caña, un bien transable que reforzó circuitos locales y que lo convirtió en un producto de consumo generalizado por la sociedad rural. Muchas de estas propiedades fueron constituidas por comerciantes huancaínos, entre los que destacaba Benigno Peñaloza, cuyas haciendas iban hasta el vecino departamento de Huancavelica.

Hasta muy entrado el siglo XIX, uno de los rubros más importantes del comercio huancaíno era el aguardiente que era consumido en el abigarrado calendario festivo del valle del Mantaro. Los distritos de Andamarca, Comas, Santo Domingo de Acobamba, Monobamba, Uchubamba (provincia de Jauja), Surcubamba, Huachocolpa y Salcahuasi (estas tres últimas en la provincia de Tayacaja), tienen condiciones climáticas y productivas parecidas que permitió la coexistencia de fundos sub-tropicales con comunidades campesinas.

Pero es cruzando el rio Pariahuanca (Fig.2) que separa ambos departamentos que se constatan diferencias históricas y culturales: los pueblos wankas son dinámicos e independientes, la zona huancavelicana muestra más bien, costumbres rígidas. Pariahuanca en resumen, está contenido por el río que lleva su nombre (que avanza sobre un área de 874 kilómetros) y el San Fernando, ambos discurren hacia el río Mantaro que dobla por última vez en su curso oriental por Chiquiac (Tayacaya), antes de ingresar hacia la selva y encontrase con el Ene.

Cincelada por el Huaytapallana —de 5,500 metros - la zona alberga una impresionante geografía que combina las punas, la zona quechua, los pequeños pisos de yunga y las laderas secas, compartidas por las 17 comunidades campesinas que conforman el distrito.

\section{CUADRO 5}

\section{PARIAHUANCA: COMUNIDADES CAMPESINAS}

\begin{tabular}{|c|c|c|}
\hline \multirow[t]{2}{*}{ Comunidades Campesinas } & \multicolumn{2}{|c|}{ Agroecología } \\
\hline & Zona & Producción \\
\hline $\begin{array}{ll}\text { - } & \text { Antarpa } \\
\text { - } & \text { Huanusco } \\
\text { - } & \text { Lampa } \\
\text { - } & \text { Lucma } \\
\text { - } & \text { Paltarumi } \\
\text { - } & \text { San Balvin }\end{array}$ & Quechua & $\begin{array}{c}\text { Diversificado } \\
\text { énfasis en papa }\end{array}$ \\
\hline $\begin{array}{ll}\text { - } & \text { La Libertad } \\
\text { - } & \text { Pariahuanca } \\
\text { - } & \text { San Cristóbal de Picpis } \\
\text { - } & \text { San Francisco de } \\
& \text { Llacsapirca } \\
\text { - } & \text { Nueva Esperanza }\end{array}$ & $\begin{array}{l}\text { Quechua } \\
\text { Yunga }\end{array}$ & $\begin{array}{c}\text { Diversificado } \\
\text { granos, frutales, } \\
\text { hortalizas }\end{array}$ \\
\hline $\begin{array}{ll}\text { - } & \text { Cedruyoc } \\
\text { - } & \text { Huachicna } \\
\text { - } & \text { Manchay } \\
\text { - } & \text { Rocchac } \\
\text { - } & \text { Panti }\end{array}$ & $\begin{array}{l}\text { Puna } \\
\text { Quechua } \\
\text { Yunga }\end{array}$ & $\begin{array}{c}\text { Diversificado } \\
\text { Complementariedad } \\
\text { bio-zonal }\end{array}$ \\
\hline - $\quad$ Chaquicocha & Puna & $\begin{array}{c}\text { Papa, ganadería de } \\
\text { ovinos }\end{array}$ \\
\hline
\end{tabular}

Fuente: elaboración propia.

Esta imponente geografía además, fue desde muy antiguo una zona de diversas entradas y caminos que la conectan a la vez, con la ruta hacia Satipo, las punas de Concepción, Pampas y la ciudad de Huancayo. Importancia geopolítica que explica la lógica del conflicto que posteriormente se desarrollaría.

Por esta razón las guerrillas del MIR, en 1965, escogieron esta zona no solo para su aventura foquista sino también para huir rápidamente: Pucuta, Ranrapata y Andamarca, por ejemplo, son lugares equidistantes, tomando a Lampa la capital del distrito como referencia. 
trabajaba en el corral cuidando de que los becerros no se mezclen con la vacas que eran ordeñadas. En eso, en un descuido, los becerros vencen al niño y se arma una trifulca, vino el hacendado y pegando e insultando al niño, que era de mi edad, coraje me había dado». Luego agrega: «Por eso cuando llegó la subversión, los abusos se han acabado, el hacendado tuvo que huir con lo que tenía puesto, y la hacienda quedó en manos de la comunidad, aunque me he enterado que los familiares están haciendo juicio para recuperar sus terrenos, pero ya la comunidad no lo va a permitir», dice Luis Q.C. de Chaquicocha.

Otro, Félix B., de Pariahuanca pueblo, dice: «Pariahuanca siempre está poco desarrollado porque antes el pueblo estaba rodeado de puras haciendas de caña; cuando nuestros animales entraban a la hacienda, los dueños nos hacían pagar demasiado e incluso se quedaban con nuestros caballos o vaquitas». Esta situación nos hace recordar lugares como Abancay, que no solo estaban rodeadas de haciendas impidiéndoles crecer, sino que incluso administraban la vida local de acuerdo a sus intereses particulares.

El hecho de que la capital del distrito sea Lampa y no el pueblo de Pariahuanca, se debe a la pugna y al triunfo de las comunidades sobre los intereses ya debilitados de los hacendados locales. Si bien la historiografía ha señalado la casi ausencia de haciendas en el valle del Mantaro, los propietarios huancaínos las poseían en otros lugares como Pariahuanca.

Así Huanusco era propiedad de la familia Badaracco. San Balvín y Viejo de Moisés Scárneo Dorregaray, Challhuas y Antarpa Chico y Grande de la familia Peñaloza, Huaribamba de los hermanos Sosa, Margarita de los Villanueva, San José de los Alcázar, Chuquipirhua de la familia Canales y Los Ángeles de Morales. Este escenario fue modificado por la reforma agraria que instaló la Cooperativa "Atahualpa» que fracasaría al poco tiempo. Ese sería el paisaje que encontrarían los guerrilleros.

Cuando en 1989 se instalan las bases militares en Santa Rosa de Ilá, Lampa y Vilcacoto (localidad de Huancayo que es la entrada hacia Pariahuanca), también se organizan las rondas campesinas, estableciendo Juntas de Defensa en las comunidades cercanas a la capital distrital. La primera ronda de autodefensa fue creada en febrero de 1990 y para 1995, existían según Guerrero (2004) 35 comités que agrupaban a cerca de 2,000 ronderos (personalmente dudo que hayan existido tantos).
En 1994, cuando se retira el Ejército, la zona estaba "pacificada" y la población rural volvió a su vida normal, esta vez estimulada por el avance de la carretera hacia el «interior», la instalación de luz eléctrica y los niveles crecientes de inversión pública.

Hoy el balance no es tan dramático como en otras regiones, pero tampoco despreciable si valoramos la zozobra y las vidas descontadas. Se estima en unos 30 los muertos durante el conflicto, la mayoría como consecuencia del enfrentamiento SL/MRTA, como el sucedido en Miotambo, o las escaramuzas en la hacienda San José o Chuyas.

Las acciones punitivas contra la población no fueron considerables. En 1988 Sendero expulsa al Centro de Servicios Campesinos (CESCA) una Ong vinculada al MIR y dirigida por los hermanos Reynoso, que eran financiados por OXFAM en la zona de Lampa, camuflando su labor política con la promoción rural. Ese mismo año, SL destruye las instalaciones del Centro Experimental de Tuna y Cochinilla que había instalado en Huaribamba la Corporación Departamental de Desarrollo de Junín (Corde Junín).

Por otro lado, Humberto Calderón, posiblemente huancavelicano, llegaría por los años 60 como administrador de la hacienda Huanusco. Fue regidor por el distrito en 1973, dirigente comunal y luego fundador regional del MRTA.

\section{2 ¿Liderazgo rural?}

Cuadro 6

PARIAHUANCA, ALCALDES 1991-2014

\begin{tabular}{|c|c|c|}
\hline Alcalde & Año & $\begin{array}{l}\text { Agrupación o movimiento } \\
\text { político }\end{array}$ \\
\hline Venancio Alhua Meza & 1991 & Movimiento Clasista Peruano \\
\hline Asunción Suárez Suazo & 1995 & Acción Popular \\
\hline Isidoro Martel Poma & 1998 & Somos Perú \\
\hline Humberto Romero Inocente & 2002 & Renacimiento Andino \\
\hline Oscar Janampa Cotera & 2006 & Restauración Nacional \\
\hline Mesías Quispe Gamarra & 2010 & Acción Popular \\
\hline Mesías Quispe Gamarra & 1014 & Acción Popular \\
\hline
\end{tabular}

Fuente: JNE-INFOGOB

Hoy Pariahuanca sigue reteniendo el poder local desde su capital y su hinterland. El Cuadro 6 nos muestra cierta continuidad política pero con sus matices. Cuando empieza el conflicto era alcalde un militante de Izquierda Unida, vinculado al Partido 
Comunista Unidad. Luego de la violencia, serán los «independientes» vinculados a algunos partidos políticos los que se alzan del poder local (aunque en 1989 gana un candidato aprista con el 100\% de los votos, aparentemente con un electorado desorganizado, se fraguó ese resultado). En 2014 la izquierda regional del Bloque Popular y el Movimiento Etnocacerista de Junín se alzan con el $23 \%$ de los votos distritales.

Figura 3

VÍCTIMAS DEL CONFLICTO INTERNO EN EL VALLE DEL MANTARO 1980-2000

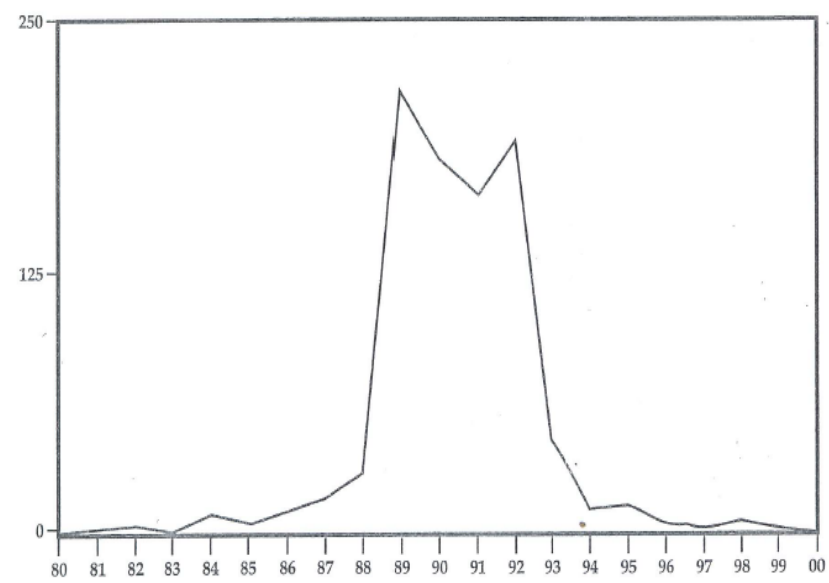

Fuente: AH 2011: 49.

Sin embargo su principal debilidad es la dispersión poblacional, eso hace por ejemplo, que el municipio solo sesione los días miércoles cuando se realiza la feria de Lampa, es ahí cuando llegan los regidores desde Huancayo, donde generalmente residen.

El hecho que el actual alcalde este preso por corrupción desde julio de 2015, indica que no se ha podido superar la desarticulación y que las comunidades del «interior» sigan con su lógica propia, muchas veces disociada de la zona nuclear de la capital distrital. Pareciese que si antes, el aislamiento adormeció la conciencia y las iniciativas locales, hoy su conexión rápida con Huancayo surte el mismo efecto.

\section{Conclusiones}

Las dos áreas someramente comparadas si bien estuvieron bajo el mismo contexto de violencia política, sus características produjeron escenarios diferentes y distintos niveles de liderazgo local. En el valle del
Canipaco si bien existieron haciendas con un notable desarrollo tecnológico, también el poder y liderazgo de las comunidades fue importante. No solo asistieron a una oleada de movilización por la tierra, sino que además fueron partícipes de las iniciativas sindicales del partido aprista desde los años 1940. Además, el hecho de que fueran comunidades «letradas» hizo que su liderazgo sea más consecuente, con objetivos locales claros y con relativa participación. Su articulación eficiente al ser una suma de distritos pequeños y compactos ha sido favorable para su evolución política (ver Figura 1).

Pariahuanca en cambio es un distrito con población rural diseminada, con una mayor diversidad productiva y de niveles de desarrollo. Esa diversidad hizo que los niveles de participación y liderazgo sean más difusos y que los impactos de inversión local sean percibidos solo fragmentariamente. La carretera que es una obra importante, los vincula horizontalmente en una zona cuyo manejo de recursos es aún vertical.

Así mismo, el hecho que se hayan producido dos emboscadas de consideración en contra del Ejército en Tintay Punco (Tayacaja) en el 2008 y Pasla Alta en Santo Domingo de Acobamba en abril del 2016, ha hecho que esta zona sea de interés gubernamental incorporándola al plan VRAEM. Las nuevas bases militares de Pariahuanca y de Huayllapata en San Antonio de Alegría, lo atestiguan.

\section{Referencias bibliográficas}

Armendariz E., F. Jaramillo y L. F. Zegarra (2011). Las barreras al crecimiento económico de Junín. Lima: BID/ CIES.

Arzobispado de Huncayo [AH] (2013). Haciendo Memoria para construir la reconciliación y la paz: Historia de la violencia politica en la región Junín 1980-2000. Huancayo: Cáritas/Arzobispado de Huancayo.

Comisión de la Verdad y la Reconciliación (CVR) (2003). Informe final. Lima: CVR.

Chanud C. y R. Ríos (1978). «Waraqumachay: un complejo pre-agrícola y de arte rupestre en el distrito de Vilca, Huancavelica», en III Congreso Peruano del Hombre y la

7 El líder senderista Oscar Ramírez Durand «Feliciano» fue capturado en Cochas Chico al norte de Huancayo, cuando venía desde Pariahuanca, huyendo de un cerco militar provocado por la delación de una colaboradora. 
Cultura Andina. Actas y Trabajos, T.II: 571-583, Lima: UNMSM (Ramiro Matos Edit.)

Durand, A. (2006). «Revalorización étnica y representación política: los casos de Inti y Mincap de Lircay, Huancavelica", en Perú: El problema agrario en debate, Sepia XI, Lima: Sepia/Oxfam/CIES: 541-481.

Guerrero Bravo, J. C. (2004). Pasado, presente y futuro de las rondas campesinas antisubversivas en Junin, Perú (1990-2001). bibliotecaclacso.edu.ar/clacso/ becas/20110124032438/7Guerrero.pdf.

Manrique, N. (1992). Mercado interno y región. La sierra central, 1820-1930. Lima: DESCO.

Martínez Alier, J. (1973). Los huacchilleros del Perú: dos estudios de formaciones sociales agrarias. Lima: IEP/Ruedo Ibérico.

Mayer, E. (1981). Uso de la tierra en los Andes. Ecología y agricultura en el valle del Mantaro con referencia especial a la papa. Lima: Centro Internacional de la Papa.

Medianero Burga, M. (1983). El Canipaco y la SAIS Cahuide. Huancayo: CICEP.
Montoya, R. et al. (1974). La SAIS Cabuide y sus contradicciones. Lima: UNMSM.

Peñaloza Jarrín, J. B. (1995). Huancayo: historia, familia y región. Lima: Instituto Riva Agüero/PUCP.

Plasencia Soto, R. (2014). «Nuevos movimientos sociales y discurso étnico en Huancavelica», en Perpectivas latinoamericanas (11): 99-111.

Reina Orozco, P. (2003). «La masacre del Canipaco», en Para no olvidar. Testimonios sobre la violencia politica en el Perú. Jorge Bracamonte et al. Lima: Red para el Desarrollo de las Ciencias Sociales en el Perú.

Remy, M. I. (1976). «Proceso y límites de la proletarización en Laive», en B. Maza et al. Capitalismo y campesinado en el Perú: aproximaciones a partir de la economía política. Lima: PUCP

Sмiтн G. (1989). Livelihood and resistance. Peasants and the politics of land in Peru. Berkeley: University of California University Press. 